\title{
Change Research on College English Teacher's Role in Information Age Zhenwen $\mathrm{Hu}$
}

Foreign Language Department of Xinxiang University, Xinxiang, Henan 453003

\begin{abstract}
Rapid development of multi-media information technology and English globalazition bring new challenge for Chinese English education. It also brings forward new requirements for college English teachers' role in the teaching process. Based on the analysis of multimedia-assisted English teaching, this paper will reconsider and define teachers role in multimedia-assisted foreign language teaching, and then explore ways and means to realize the role change.
\end{abstract}

Keywords: Multi-Media teaching; College English teaching; Role of teachers

\section{信息时代大学英语教师角色的转变探究}

\author{
胡桢文 \\ (新乡学院大学外语部 河南 新乡 453003)
}

摘要: 多媒体信息科技的迅猛发展和英语的全球化给我国英语教育带来了新的挑战, 也对大学英语教师在教学过程中所 扮演的角色提出了新的要求。本文从分析多媒体辅助英语教学出发, 重新考虑并定义多媒体辅助外语教学中的教师角色, 进 而探究实现角色转变的方法与途径。

关键词: 多媒体教学; 大学英语教学; 教师角色.

引言

随着教育部 2004 年大学外语教改政策与措施的出台和实施, 多媒体教学新模式使现代外语教学发生 了巨大的变革, 也因此成为外语教学领域中的一个研究与实践热点。然而, 通过对教育部几所教改试点院 校及一些非试点普通二级本科院校的调查发现, 尽管教改成果显著, 但是一些不容乐观的问题也不断凸现 或继续存在。关于教师如何真正有效地应用多媒体技术提高大学英语教学的探究与实践尚未得到足够重 视, 实际教学效果与预期有所偏差。同时, 在新形势下, 教师继续仅凭有限的知识或者是所谓的权威来实 施课堂教学, 已经很难驾驭课堂和吸引学生, 教师的传统角色和定位已经受到了前所未有的挑战 ${ }^{[1]}$ 。因此, 如何正确看待多媒体辅助英语教学, 怎样合理定位自身角色并成功转变以适应这一全新的教学模式, 已经 成了当今大学英语教师的当务之急。

\section{1 正确看待多媒体辅助大学英语教学}

我国的多媒体英语教学可分为三种: 演示型多媒体即教室大屏幕投影教学、人手一机独立自主学习及 网络远程教学。其中, 绝大多数学校采用的是大屏幕投影教学模式, 占 $70.6 \%$, 是多媒体教学的主要形式 ${ }^{[2]}$ 。

语言教学采用计算机多媒体投影方式有很多优势。根据认知主义学习理论, 语言学习的立体输入强于 单一的视觉或者听觉的输入, 教师在正常的语言教学中部分地采用多媒体来演示语言现象, 尤其是采用图、 文、声、像多媒体立体语言教学, 其优势比较明显, 它具有形象化、多样化、生动化的特点, 有利于语言 教学的多方位立体输入、突出重点、提高学生的学习兴趣和记忆力 ${ }^{[3]}$ 。

尽管多媒体投影教学具有很多传统教学模式无法相比的优点, 但计算机代替不了教师, 特别是在英语 语言的教学和学习中, 教师的主导作用更不容忽视。过多地使用多媒体, 完全不加区别地将多媒体光盘作 
为演示内容呈现给学生, 只能将多媒体教学变成运用现代手段的知识灌输课, 不仅不利于学生的学习, 更 影响师生的课堂互动, 影响语言教学的效果和质量; 而如果因为害怕计算机会取代教师的位置而一味抵制 对计算机等多媒体技术的引进, 又未免思想太僵化。对于大学英语教师来讲, 只有正确认识多媒体教学, 既不过分依赖多媒体, 又不忽视多媒体的优势, 才能正确应对当前的教学模式变化, 合理地定位自身的角 色。

\section{2 合理定位大学英语教师的角色}

随着多媒体技术越来越广泛的应用在辅助大学语教学上, 大学英语教师在整个英语教学过程中的角色 也由原来单纯的知识传授者转变为以下的多元化的角色。

\section{1 教学组织者}

在大学英语教学活动中如何有效的应用多媒体技术, 发挥多媒体的辅助作用, 以及怎样实现现代教育 技术与传统语言教学的整合和优化, 都离不开教师的作用。教师要事先对课程计划进行统筹设计, 对教材、 课件、学生需求进行认真分析, 确定教学目标, 选择适当的教学方法, 在实际操作中, 不仅注意到多媒体 技术与听说读写等语言学习完美结合, 更需要关注学生的表现, 根据学生的课堂反馈适时灵活地调整教学 模式和教学方法, 才能确保师生交流与互动的实现, 保证学习过程的良性发展。这一切都说明教师作为教 学组织者在大学英语教学过程中的重要性。

\section{2 学习指导者}

在网络时代，信息技术打破了以前教师所独享的知识 “霸权” 和 “垄断” 地位，师生交往趋于多样化 平等化。 ${ }^{[4]}$ 在以网络和多媒体为基础的新的教学模式下, 课堂教学就不能仅仅局限于课本知识和语言的用 法了, 特别是在大学的英语课堂上, 教师更应该引导学生如何学习, 如何掌握学习方法提高学习效率, 如 何发现问题并解决问题, 在获取知识的同时发展能力, 也就是把 “教” 变为 “导” , 才能够促进和帮助学 生更好地掌握英语。

\section{3 平等的学习者}

在网络时代，大学英语教师不仅要具有扎实的语言知识理论和基础，还应该掌握先进的现代教育技术 手段, 熟练制作课件, 充分利用网络上的外语资源, 这些都要求教师要不断地充实自己。为了取得良好的 教学效果, 教师还要尽可能的与学生交流, 关注并理解学生的情感和需求, 更加努力的开展各种语言交流 活动, 与学生一起参与到活动中去, 体验他们的感受, 让学生感受到老师的真诚并消除紧张感。在教学的 过程中, 教师也是虚心的学习者, 要不断地总结方法, 向学生学习向其他老师学习, 总之, 新的教学模式 下的大学英语教学对教师本身提出了更高的要求, 教师应该通过不断地学习来提升自己的教学水平和科研 水平, 才不会落后于时代。

\section{4 教学研究者与合作者}

作为大学英语教师, 要主动了解现代语言理论、外语教学和学习理论的最新理论成果, 掌握最新的教 育思想、洞悉教育发展趋势、研究方向、研究方法, 对自己的教学行为加以反思、研究并反馈于教学中, 同时, 教师还应充分利用互联网, 跨越国度、院校和领域的种种限制, 通过电子论坛或电子邮件的方式进 行交流与合作, 讨论教学方法、交换教学意见和观点、共享教学资源, 讨论教学难题, 从而提高操作计算 机和解决实际教学问题的能力。 


\section{3 成功转变教师角色的途径}

首先, 教师个人要转变教学思想和改进教学方法, 充分利用多媒体, 创设一定的语言情境, 帮助学生 培养良好的学习习惯, 掌握发现和探索式的学习方法, 从而促进和帮助学生实现自主学习。教师可以把学 习内容、要求以及教材、学习课件还有网络资源等的使用方法都给学生讲解清楚, 可以尝试给学生分组, 进行小组协作学习, 在课堂上多进行小组讨论和二人协商的课堂活动, 教师从中给予指导、帮助和评价, 引导学生进一步深入讨论, 通过频繁的师生和生生互动交流促进语言的学习。

其次, 学校有关部门要帮助大学英语教师学习掌握相关的教育信息技术, 帮助他们学会使用常用的多 媒体手段和基本的网页制作技能。比如, 学校的现代教育技术部门可抽调部分技术人员和专家, 定期为本 校的大学英语教师开展培训课和学习讲座, 把最新的多媒体操作方式和电脑技术传授给英语教师, 从而有 效地帮助英语教师解决在教学过程中遇到的许多技术性问题。

另外, 学校应尽可能地创造条件帮助英语教师更新语言知识和教学理论。通过加强图书馆建设, 增加 外语图书资源, 方便英语教师的查阅和学习; 开辟专门的机房供英语教师进行网上查询和学习; 与名校联 合, 互相观摩和学习, 加强教学合作和交流; 邀请相关的专家作有关语言学和教学理论方面的学术讲座, 为英语教师提高理论素质和教学水平提供指导和帮助。

最后, 学校还应加强教学硬件和软件的建设, 及时维护和更新教学设备, 为教师教学创造良好环境。

总之, 大学英语教师要完成自身角色的转变, 不仅需要依靠个人的努力, 还需要学校各有关部门的共 同参与和帮助, 为教师尽快创造一个学习和教学氛围都很浓的校园环境, 从而帮助教师尽快适应新的教学 模式, 实现角色的转变和定位。

\section{4 结语}

多媒体辅助语言教学正在随着现代教育技术的发展而迅速发展, 许多语言教师越来越清楚地认识到了 其在语言教学中所起的重要作用, 因而努力学习计算机知识, 以适应时代发展的需要。多媒体辅助语言教 学虽然不会完全取代传统的语言教学方式, 但它对语言教学的影响决不容忽视, 两者各有优势, 不能互相 取代, 教师只有认清自己在教学过程中所扮演的角色, 把多媒体辅助语言教学融合到传统的课堂教学中, 使二者达到有机结合, 语言教学才能取得最好的效果。

\section{参考文献:}

[1] 崔岭. 多媒体投影式大学英语课堂教学模式: 学生角色探析 [J]. 外语界, 2004, (2): 48.

[2] 郭珊. 多媒体教学英语教师角色的负面影响及对策 [J]．绵阳师范学院学报，2008，27（9)：148.

[3] 李萌涛.多媒体投影英语课堂教学初探 [J]. 外语界, 2001, (3): 66.

[4] 袁小陆. 大学英语教学改革中教师角色的转变 $[\mathrm{J}]$. 西安邮电学院学报, 2006, 11 (1): 127 .

作者简介: 胡桢文, 1981 年生, 女, 陕西省宝鸡市 (籍贯), 讲师 (职称), 研究生 (学历), 研究方向: 英语教育

\section{References:}

[1] Cui Ling. Teaching Mode of College English Classroom with Multimedia: Research on Students Role [J].Foreign Language World, 2004, (2):48 
[2] Guo Shan. Negative Influence and Countermeasures of Teachers Role in Multimedia English Teaching [J].Journal of Mianyang Teachers' College,2008,27(9):148

[3] Li MengTao. Research on English Teaching in Multimedia Projection [J]. Foreign Language World, 2001, (3): 66.

[4] Yuan XiaoLu. Change of Teacher's Role in College English Teaching Reform [J]. Journal of Xi'an Institute of Posts and Telecommunications, 2006, 11(1):127.

About the author: Hu Zhenwen, born in 1981, female, Baoji City, Shaanxi Province (place of birth), lecturer (title), postgraduate (education), research direction: English education 